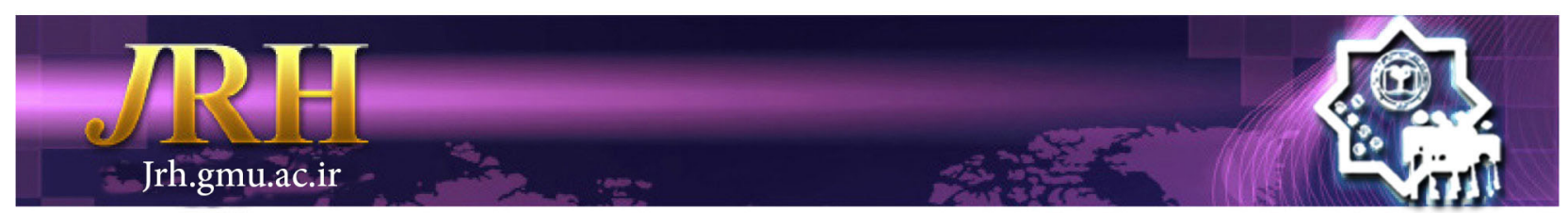

\title{
The attitudes toward extramarital relations and some of its related factors among families of Tabriz
}

Mohammad Abbaszadeh", Samad Adlipour², Mohammad Bagher Alizadeh Aghdam¹, Tavakkol Aghayari Hir ${ }^{1}$

\author{
Journal of Research \& Health \\ Social Development \& Health Promotion \\ Research Center \\ Vol. 9, No. 6, Nov \& Dec 2019 \\ Pages: $496-504$ \\ DOI: 10.32598 /jrh.9.6.496 \\ Original Article
}

1. Department of Social Sciences, Faculty of Law and Social Sciences, University of Tabriz, Tabriz, Iran

2. Correspondence to: Department of Sociology, Faculty of Law and Social Sciences, University of Tabriz, Tabriz, Iran

Email: s.adlipour@tabrizu.ac.ir

Received: 11 Mar 2019

Accepted: 9 Jun 2019

How to cite this article: Abbaszadeh M, Adlipour S, Alizadeh Aghdam MB, Aghayari Hir T. The attitudes toward extramarital relations and some of its related factors among families of Tabriz. J Research \& Health2019; 9(6): 496 - 504.

\begin{abstract}
Extramarital relations are the most common social problems with many negative consequences on family institution, including erosion of mutual marital trust and divorce. A study on the attitudes of people in society towards extramarital relations can be an important indicator in predicting this behavior. The present study to investigate the attitudes toward extramarital relations and some of its related factors. The research was a correlation survey, and the statistical population consisted of married women aged 18-60 years old in Tabriz city in 2018. 510 participants were selected as sample of studythrough the multi-stage cluster sampling technique. The data collection instrument was a researcher-made questionnaire on attitudes toward extramarital relations, familism, social reflexivity, and religiosity. The findings show that with increasing familism and religiosity, participants' attitudes toward rigorous or negative outcomes of extramarital relations become significant, while with increasing satellite networks usage and virtual social networks usage, their attitudes toward extramarital relations become positive. In addition, the predicted variables in the regression model of the study can explain $36 \%$ of the changes in attitudes toward extramarital relations. By increasing the level of adherence to family values and the adoption of appropriate family policies and decisions and its challenges, it is possible to significantly reduce the individuals' negative or positive attitudes towards extramarital relations.
\end{abstract}

Keywords: Communication Media, Extramarital Relations, Family, Religion

\section{Introduction}

Family, as one of the most important social institution, has always a special status during the history in all societies. This institution, apart from its long responsibility for continuity of the generations and the survival of human beings, it has had some duties and roles such as economic activity, regulation of sexual relations and socialization of the individuals [1]. However, over the past few decades, the family institution has undergone significant changes, which have brought challenges against the functions and traditional structure of the Iranian family [2]. One of the challenges is the extramarital relationship that is a 
common phenomenon in today's societies [35]. Extramarital relations can be considered as violations of the obligations among the couples in marital relations. Such breach of obligations results in the formation of affection or sexual intercourse with another person outside the marital relationship [6]. Extramarital relations often occur to meet one's emotional or sexual needs. This is not necessarily a sexual relationship, but this type of relationship is based on secrecy [7].

So far, numerous studies have been conducted about extramarital relationships in Iran and the other countries. Mark and his colleagues regard the lack of satisfaction from sexual relations or dissatisfaction with the current marital relationship as predisposing factors of the extramarital relationships among the couples [8]. Longing for diversity and sexual excitement, revenge, lack of couples' attention to each other, loneliness and lack of security in life are also other factors leading to extra marital relationships $[9,10]$. Some research finds the weakness of religious beliefs as the main factor in the tendency towards extra marital relationships $[11,12]$.

Olson and his colleagues consider dissatisfaction with marriage and inappropriate marriage as the main factor for engaging in extramarital relationships [13]. In some research conducted in Iran, more attention is paid to studying the relationship between factors such as attachment styles [14,15], responsiveness, depression, aggression, phobia and psychosis [16], early maladaptive schemas [17], religious, marital conflicts and porn movies [18], sexual dissatisfaction, emotional and behavioral problems in marriage [19], programs and serials of persian-language satellite networks [20,21] and extra marital relationships.

Although the extramarital relations in most of the countries allocate a large number of research, and in Iran, this topic has been studied from psychological approach, specific cultural, religious and social conditions in Iran have prevented doing comprehensive studies and particularly sociological evaluation [22].
However, from the sociological point of view, due to the globalization and the influence of modern values (especially through the modern media) in developing countries, attitudes of people in these societies have changed and people rethink about their traditional and religious values so that we regularly witness the emergence of new patterns of sexual interaction, such as the friendship with the opposite sex after marriage and the extramarital relations [23]. On the other hand, any changes in the attitudes of people in society towards extramarital relations can be an important indicator forpredicting the tendency of people for extramarital relations, because these beliefs and values encourage or discourage the people's involvement in extramarital relations [24]. In this regard, the findings of Treas and Giesen show that those who have a positive or attentive attitude toward extramarital relations are more likely to engage in extramarital relationships [25]. Therefore, for making a decision and planning for preventing extramarital relationships, it is necessary to study the attitudes of married people about the extramarital relationships and the factors affecting it. Therefore, the aim of this study is to evaluate the attitudes of married people in Tabriz toward the extramarital relations and some of its related factors (religious, familism, social reflexivity, the modern media usage).

\section{Method}

This research is a correlation survey, and its data were collected through a questionnaire in the fall and winter of 2018 in Tabriz city, the northwest of Iran. The statistical population of this study includes Tabriz' households who, based on the statistics of the population census and housing, were 563660 in 2016. The sample size is estimated 510 participants by the Cochran formula.

Sampling method is a multistage cluster sampling. It was conducted as follows: in the first stage, each of the ten regions of the municipality of Tabriz was considered as a cluster. In the second stage, list of 
neighborhoods from each region was prepared and in each district, one of the neighborhoods was selected randomly and then the questionnaires were completed. In neighborhoods, due to the lack of a list of names and number of married people, the available people were used. The following scales have been used to measure the research variables.

A researcher-made questionnaire was used to measure the attitude toward extramarital relations. This scale is measured using 6 items in the form of Likert scale (from completely disagree to completely agree). For determining the validity of items, the formal (qualitative and quantitative) and content validity methods Content Validity Ratio and Content Validity Index (CVR and CVI) were used. To determine the qualitative formal validity of the questionnaire, 10 experts (4 sociologists, 3 social workers, 3 family counselors) were given a questionnaire to determine the level of difficulty, the incompatibility and vagueness of sentences and clauses.

According to the experts, out of 8 items, 2 cases overlapped with other questions, and one case was not related to the attitude toward childbearing. After applying the opinions of these experts, a total of six items were identified for the attitude towards extra marital relations. To determine the quantitative validity, the opinions of 20 married men and women in Tabriz city regarding the difficulty of understanding the questions, the ambiguity and misunderstandings, and the proportionality and suitability of the questions were separately used in the Likert scale, and for the criterion of proportion and relation of the cases, Beta coefficient was used. The results showed that the agreement was over $80 \%$ and its score was 1.5. Also, to determine the index of content validity, the questionnaire was given to 10 experts or specialists in sociology, counseling, and psychology, and asked them to answer 6 questions as: "necessary", "not necessary", "useful" and "not necessary". Using CVR formula and comparing with Lawshe table, numbers over 0.62 were accepted.

In addition, to assess the content validity index using the Waltz \& Bausell method, the questionnaire was returned to the specialists and they were asked to comment on each of 6 questions as 1) non-relevant 2) partially relevant, 3) relevant, 4) fully relevant. Totally, CVI score was obtained were 3 and 4 and the scores were accepted based on CVI score which was more than 0.79 . The questionnaire range is between 6 and 30 so that respondents with an overall score of 30 or close to 30 have a strict attitude towards extramarital relations, and those who have a total score of 6 or close to 6 have a loose attitude towards this type of relationship. The reliability of the items was measured by Cronbach's alpha coefficient and it was 0.81 .

A researcher-made questionnaire has been used to measure the social reflexivity. To do this, 17 items have been used in the form of a Likert scale (completely disagree to completely agree). The formal (qualitative and quantitative) and content validity (CVR and CVI) of the questionnaire was confirmed in the above manner. The range of the questionnaire is from 17 to 85 so that the respondents whose score was from 17 to 66.39 , they have a low reflexivity, with a score from 39.67 to 62.27 , with a modest reflexivity, and those with a score from 62.28 and 85 , they have a high degree of reflexivity. The reliability of the items was measured by Cronbach's alpha coefficient and it was 0.88 . A researcher-made questionnaire has been used to measure the familism. To do this, 17 items have been used in the form of a fivechoice Likert spectrum (completely disagree to completely agree). The formal (qualitative and quantitative) and content validity (CVR and CVI) of the questionnaire was confirmed in the above manner. The questionnaire was scored from 8 to 40 so that the respondents with an overall score of 8 to 18.66 had low familism; those with an average score of 18.67 to 29.33 , they had moderate familism, and those with an average score of 29.34 to 40, had a high familism. The reliability of the items was measured by Cronbach's alpha coefficient and it was 0.83 . 
A researcher-made questionnaire was again used to measure the religiosity of the subjects. Religiosity includes four ritual, consequential, emotional and religious dimensions. This scale has been measured using the five-choice Likert scale with 21 items. The formal (qualitative and quantitative) and content validity (CVR and CVI) of the questionnaire was confirmed in the above manner. The questionnaire ranged from 21 to 105 so that the respondents with a general score from 21 to 49 had low religiosity, those with a score of 49.01 and 77.01 had moderate level of religiosity, and those with a score of 77.02 and 105 had a high degree of religiosity. The reliability of the items was measured by Cronbach's alpha coefficient and its value was 0.93 for belief dimension, 0.92 for emotional dimension, 0.88 for religious dimension, 0.86 for consequence dimension and totally it was 0.95 .

The rate of modern media usage (satellite networks and virtual social networks such as Telegram and Instagram) was measured in terms of the amount of time a person spends on the media during a week. The observance of the principles of secrecy and keeping the confidential information, and the freedom of the subjects to leave the study were among the ethical principles observed in this research. The data were analyzed using SPSS 22 and descriptive statistics (frequency, mean, standard deviation) and inferential statistics (t-test, F, Pearson correlation and multiple regression tests) were used (significance level $<0.05$ ).

\section{Results}

The descriptive findings of the research indicate that the respondents are from 18 to 60 years old and the ageaverage and standard deviation is $37.81 \pm 11.52$ years. The average of women age was $38.27 \pm 11.97$ and the average of men age was $37.30 \pm 10.99$. They also show that $52.7 \%$ of respondents were female and $47.3 \%$ are male. In terms of socioeconomic status, $20 \%$ of the respondents are from low class, $26 \%$ from middle class, $32 \%$ from the upper middle class and $22 \%$ from the upper class.

Table 1 shows that there is a significant difference between married women and men's attitudes toward extramarital relationships. It means that women's attitudes toward extramarital relations are more negative or stricter than men, and men have a loose or positive attitude toward extramarital relationships $(p<0.003)$. Also, there is no significant difference between the mean of attitudes toward extramarital relationships in terms of socio economic status, and all classes have similar attitudes toward this kind of relationships ( $p>0.274)$.

\begin{tabular}{|c|c|c|c|c|c|c|}
\hline Variable & Groups & $\mathrm{N}$ & Mean & Std. Deviation & $\mathrm{T}, \mathrm{F}$ & sig. \\
\hline \multirow{2}{*}{ Gender } & Female & 269 & 24.910 & 5 & \multirow{2}{*}{3.025} & \multirow{2}{*}{0.003} \\
\hline & Male & 241 & 23.489 & 5.549 & & \\
\hline \multirow{4}{*}{$\begin{array}{l}\text { Socio economic } \\
\text { status }\end{array}$} & High & 113 & 23.495 & 5.719 & \multirow{4}{*}{1.300} & \multirow{4}{*}{0.274} \\
\hline & Over average & 165 & 24.769 & 4.730 & & \\
\hline & Under average & 135 & 24.274 & 5.355 & & \\
\hline & Low & 97 & 24.239 & 5.650 & & \\
\hline
\end{tabular}

The information in Table 2 shows that there is a significant correlation between familism and religiosity with extramarital relations. That is, attitudes towards the extramarital relationship (positive or negative) depend on the rate of familism and religiosity. Also, it can be seen that there is a significant correlation between the social reflexivity, the use of satellite networks and virtual social networks and attitude towards the extramarital relationships. It means that any increase in the social reflexivity and the use of modern media will lead to changes in theattitudes towards extramarital relations.

Table 3 shows the multiple regression model of the attitude towards extramarital relations. All regression assumptions, such as the lack of coherence between independent variables, the independence of errors or residues, and the 
normal distribution of errors, were confirmed. The information in this table shows that the multiple correlations $(0.60)$ indicate that the predictive variables are simultaneously related to the attitudes towards the extramarital relations. The determination coefficient was 0.36 . It means that $36 \%$ of the changes in attitudes toward the extramarital relations are explained by predictive variables. The Beta coefficient in this Table shows that the strongest predictors of tendency towardsExtra marital relations were familism $(0.48)$, religiosity $(-0.19)$, the use of satellite networks (0.16), and the virtual social networks usage (0.14). Also, it showed that social reflexivity does not have a significant effect on people's attitude toward extramarital relations

Table 2 Correlation test between research variables

\begin{tabular}{|c|c|c|c|c|c|c|}
\hline & Familisim & Religiosity & $\begin{array}{c}\text { Social } \\
\text { reflexivity }\end{array}$ & $\begin{array}{c}\text { Virtual social } \\
\text { networks }\end{array}$ & Satellite networks & Extramarital \\
\hline \multirow{2}{*}{ Familisim } & & $0.48 * *$ & $-0.21 * *$ & $-0.22 * *$ & $-0.21 * *$ & $0.57 * *$ \\
\hline & & 0.001 & 0.001 & 0.001 & 0.001 & 0.001 \\
\hline \multirow{2}{*}{ Religiosity } & $0.48 * *$ & & $-0.40 * *$ & $-0.33 * *$ & $-0.34 * *$ & $-0.42 * *$ \\
\hline & 0.001 & & 0.001 & 0.001 & 0.001 & 0.001 \\
\hline \multirow{2}{*}{$\begin{array}{l}\text { Social } \\
\text { reflexivity }\end{array}$} & $-0.21 * *$ & $-0.40 * *$ & & $0.28 * *$ & $0.31 * *$ & $0.19 * *$ \\
\hline & 0.001 & 0.001 & & 0.001 & 0.001 & 0.001 \\
\hline \multirow{2}{*}{$\begin{array}{l}\text { Virtual social } \\
\text { networks }\end{array}$} & $-0.22 * *$ & $-0.33 * *$ & $0.28 * *$ & & $0.84 * *$ & $0.18^{* *}$ \\
\hline & 0.001 & 0.001 & 0.001 & & 0.001 & 0.001 \\
\hline \multirow{2}{*}{$\begin{array}{l}\text { Satellite } \\
\text { networks }\end{array}$} & $-0.21 * *$ & $0.34 * *$ & $0.31 * *$ & $0.84 * *$ & & \multirow{2}{*}{0.14} \\
\hline & 0.001 & 0.001 & 0.001 & 0.001 & & \\
\hline \multirow{2}{*}{$\begin{array}{l}\text { Extramarital } \\
\text { relationships }\end{array}$} & $0.57 * *$ & $0.42 * *$ & $0.19 * *$ & $0.18 * *$ & 0.14 & \multirow{2}{*}{0.002} \\
\hline & 0.001 & 0.001 & 0.001 & 0.001 & 0.002 & \\
\hline
\end{tabular}

$* * \mathrm{p}<0.01$

Table 3. Multiple regression model of attitudes towards extramarital relations

\begin{tabular}{|c|c|c|c|c|c|c|c|c|c|c|}
\hline Variables & $\mathrm{B}$ & Beta & $\mathrm{t}$ & Sig & Tolerance & $\mathrm{R}$ & $\mathrm{R}^{2}$ & $\mathrm{~F}$ & sig. & Durbin-Watson \\
\hline Familism & -0.445 & -0.48 & -11.76 & 0.001 & 0.76 & \multirow{5}{*}{0.60} & \multirow{5}{*}{0.36} & \multirow{5}{*}{57.72} & \multirow{5}{*}{0.00} & \multirow{5}{*}{2.116} \\
\hline Religiosity & -0.057 & -0.19 & -4.298 & 0.001 & 0.89 & & & & & \\
\hline Satellite networks & 0.427 & 0.16 & 2.374 & 0.018 & 0.70 & & & & & \\
\hline $\begin{array}{l}\text { Virtual social } \\
\text { networks }\end{array}$ & $0 . .374$ & 0.14 & 2.149 & 0.032 & 0.69 & & & & & \\
\hline Social reflexivity & 0.011 & 0.02 & 0.549 & 0.583 & 0.80 & & & & & \\
\hline
\end{tabular}

\section{Discussion}

Findings of the present study indicate that men, in comparison with women, have a positive or loose attitude toward extramarital relations. This finding is consistent with the findings of Abdolmaleki et al, Ghoreishi and Pourjbar, Blow and Hartnett. The findings of these studies show that men tend to pursue physical and sexual pleasures and that is why they tend to make new relationships and experience the excitement of a new sexual relationship. This is the main reason for having positive and loose attitudes toward extramarital relationships $[7,26,27]$. Other findings showed that there was no significant difference between attitudes toward extramarital relationships in terms of socio economic status and all social classes had a similar attitude towards extra marital relations. This finding is consistent with the findings of Adamopoulou, who showed that the socioeconomic status has no role in the tendency toward extramarital relationships, and it may happen in all social classes, and people have both positive and loose attitudes towards the economic and social groups. Other findings suggest that familism has a significant effect on attitudes 
toward extramarital relationships so that with increasing familism, the people's attitude toward extramarital relations changes. This finding is in line with the results of Fathi et al., Zahedi and Nazoktabar's research which showed that emotional and behavioral problems in marital life, negative attitudes toward marriage and family, and lack of attachment to family values play an important role in starting extramarital relations $[29,30]$. In the analysis of this finding, it can be said that in families in which couples have enough time to talk to each other and be together, they respect each other's views, spend their leisure time and enjoy being together and experience a sense of proximity and sincerity and consider the family as a safe place, and feel secure in it, they also have negative attitudes toward extramarital relations [31]. Also, the findings of this study showed that religiosity plays an important role in respondents' attitudes toward extramarital relationships. By increasing the level of religiosity of individuals, their attitude towards extramarital relationship becomes negative. This finding is in line with the findings of the research by Eider \& Mardani and Mattingly \& Schramm, who showed that religious people have much more negative attitude toward extramarital relations $[11,12,18]$. Therefore, it can be argued that religiosity has always been a barrier to the satisfaction of sexual instincts outside of the legal and social norms, so that religiosity delayed the attainment of sexual satisfaction and condemned the illegitimate sexual relations and encouraged individuals to observe the marital obligations [26] In addition, the research findings indicate that the use of modern media (satellite networks and virtual social networks) contribute to the formation of positive or loose attitudes toward extramarital relationships. This finding is in line with the findings of Abdolmaleki et al, Eidar and Mardani, Kamaljou et al, Dortaj et al, who showed that there is a meaningful relationship between the use of satellite networks, the Internet and virtual social networks with the tendency and involvement in extramarital relationships $[7,18,32,33]$. The use of modern media makes people familiar with the values and cultures of other countries, especially the western countries. In many cases, the values and cultures of European and Western countries are in conflict with traditional values, and this can have negative consequences. Also, if these conflicting values are not institutionalized in the person, one gets his attitude and practice, involved in fining his own way and it is likely that the lack of satisfaction in couples' relations will lead them to the extramarital relations [26]. Also, the fact that an individual remains unknown in the virtual networks, the ease and low cost of virtual extramarital relationships, and the ability of cyberspace to escape people from the real issues and problems of marital life, underlie the spread of extramarital relations among people and even among those who demand the durability of their marital life [34]. In fact, the modern media play an important role in changing the attitude of individuals towards extramarital Relations through preparing the anonymity and safely [32]. Finally, the findings of this study showed that although there is a significant correlation between social reflexivity and attitude towards extramarital relations, and those who have high social reflexivity have a more favorable attitude toward extramarital relationships, but according to regression test, this variable does not has a significant effect on people's attitudes towards extramarital relationships. Social reflexivity refers to the fact that in moving towards modernity, we have to contemplate and continually reflect on our lives. The modernity is the reflexivity on everything, and rethinking on tradition and the past values of society is one of the most important consequences of modernity rethinking [35]. During the process of reflexivity, the role of traditional patterns in directing the actions of people paled, and in the light of new information individuals can constantly transcend their actions (e.g. sexual actions) [36]. Regarding the lack of correlation between social reflexivity and the attitude towards extramarital relations, it can 
be argued that given the fact that the Tabriz is a transition society and moves from tradition to modernity and has not fully experienced the modernization process, there are still traditions whichhave dominated many aspects of the personal and social life and does notallow people to do rethinking. The most important limitation of the present study was the problem sensitivity so that which the respondents may not have answered correctly to questions or assessed their relationships in lower level.

\section{Conclusion}

The results show that attitudes toward extramaritalrelations are influenced by various personal and social factors such as gender, family, religiosity, and the extent of using the modern media. Among these factors, it became clear that familism or adherence to family values play the main role in strict attitudes towards extramarital relationships. Of course, the religiosity and the use modern media were also influential. Therefore, by increasing the level of adherence to family values and the adoption of appropriate family policies, and its challenges, it is possible to significantly reduce the negative or positive attitudes of individuals towards extramarital relations. Also, by organizing workshops on the causes and effects of extramarital relations, as well as ways to increase marital and family commitment, it becomes possible to increase the level of familism among couples, thereby make their attitudes more rigorous towards extramarital relationships.

\section{Acknowledgments}

This article is extracted from Ph.D dissertation in Sociology of Economics and Development entitled "investigating the role of modernization in family changes and transformations (the case of study: families in Tabriz city)", approved by the Faculty of Law and Social Sciences of Tabriz University. In this way, the researchers want to thank all the respondents and those who supported us in collecting the data. They also appreciate all the respondents who patiently completed the research questionnaires.
The article is from the dissertation in development and economic sociology in Tabriz university. It was justified in 2017/11/28.

\section{Authors' contributions}

Study design: MA, SA

Data collection and analysis: SA, TAH

Manuscript preparation: MA, SA, MAA, TAH

All authors have read and approved the final version.

\section{Conflict of Interests}

"The authors declare that they have no competing interests."

\section{Funding}

The author (s) received no financial support for the research, authorship and/or publication of this article.

\section{Availability of data and materials}

The datasets used and/or analyzed during this study are available from the corresponding author on reasonable request.

\section{References}

1- Mohammadpur A, Rezaei M, Partovi L, Sadeghi R. The meaning reconstruction of family changes using grounded theory (a case study of mangor and gaverk tribes). Journal of Family Research2009; 5(3): 309-30.

2- Zahedi MJ, Nayebi H, Danesh P, Nazoketbar H. Sociological explanation of modernization process effects on the family structure (comparison of urban and rural areas in Mazandaran province). Women's Strategic Studies2013; 16(61): 97-148.

3- Gordon KC, Baucom DH, Snyder DK. An integrative intervention for promoting recovery from extramarital affairs. J Marital Fam Ther2004; 30(2): 213-31.

4- Bagarozzi Sr DA. Understanding and treating marital infidelity: A multidimensional model. Am J Fam Ther2007; 36(1): 1-17.

5- Smith C, Hall R, Daigle J. Monotony in monogamy: a study of married individuals seeking to have an extramarital. Am J Psychol Res2010; 6(1): 97-102.

6- Aviram I, Amichai-Hamburger Y. Online infidelity: aspects of dyadic satisfaction, self-disclosure, and narcissisms. J Comput-Mediat Commun2005; 10(3): 74-84.

7- Abdolmaleki M, AzamAzadeh M, Ghazinezhad M. 
The relationship of global media, modern reflexivity and tendency to extramarital relationship among married couples of Qorveh city. Journal of Family Research2015; 11(43): 309-32.

8- Mark KP, Janssen E, Milhausen RR. Infidelity in heterosexual couples: demographic, interpersonal, and personality-related predictors of extradyadic sex. Arch Sex Behav2011; 40(5): 971-82.

9- Maphosa S, Mutandwa P, Nyamayaro AT. Infidelity appetite: psychological factors influencing married women to engage in extra-marital affairs. Int J Innov Res Dev2017; 6(1): 46-52.

10- Rokach A, Philibert-Lignières G. Intimacy, loneliness and infidelity. Open Psychol J2015; 8(2): 71-7.

11- Mattingly BA, Wilson K, Clark EM, Bequette AW, Weidler DJ. Foggy faithfulness: relationship quality, religiosity, and the perceptions of dating infidelity scale in an adult sample. J Fam Issues2010; 31(11): 1465-80.

12- Schramm DG, Marshall JP, Harris VW, Lee TR. Religiosity, homogamy, and marital adjustment: an examination of newlyweds in first marriages and remarriages. J Fam Issues2012; 33(2): 246-68.

13- Olson MM, Russell CS, Higgins-Kessler M, Miller RB. Emotional processes following disclosure of an extramarital affair. J Marital Fam Ther2002; 28(4): 423-34.

14- Sohrabi F, Rasooli F. The relationship between the attachment style and the extramarital sex relationship among married women in residential center for deviant women. Journal of Family Research2008; 4(2): 133-43.

15- Hojjatkhah M, Mohammadi M, Valadbeigi P. The relationship between attachment styles, personality traits and forgiveness with the attitude toward extramarital relationships in married women in Kermanshah. Journal of Women's Social Psychological Studies2016; 14(4): 209-28. 16- Karami J, Zakiei A, Mohammadi O, Haghshenas S. The role of psychosocial factors in predicting attitudes toward extramarital relationships in married women and providing a model based on related factors. Journal of Women's Social Psychological Studies2015; 13(3): 152-39. 17- Rafiei S, Hatami A, Forooghi AA. The relationship between primary adolescent schemas and attachment styles in women with marital infidelity. Women's and Society Quarterly2011; 2(1): 21-36.

18- Eider N, Mardani M. Investigation of factors related to the tendency of married men to extramarital relationships (Case study of married men in the city of Shiraz). Journal of Social Sciences2016; 10(4): 145-72.

19- Fathi M, Parvin S, Javadian SR. Comparing the causes of infidelity in marital relationships among men and women: A qualitative research. Journal of Qualitative Research in Health Sciences2016; 5(4): 401-18.

20- Ajam AA. The effect of direct and indirect satellite training on marital conflict and attitudes toward marital infidelity. Biquarterly Journal of Studies in Islam \& Psychology2016; 10(18): 125-46.

21- Firoozjayan A, Ghadiri H. Phenomenological study of marital deportation reasons. Journal of Iranian Social Studies2017; 11(1): 120-44.

22- Kamali S, Ameri F, Khosravi Z, Ramezani MA. Lived experience of women of their husbands' extramarital relationships: a phenomenological study. Journal of Family Research2018; 14(1): 95-112.

23- Soleymani M, Hashemi Z, Mohseni Tabrizi A, Nayebi H. Structural equation modeling factors influencing the rethinking of youth's sexual interactions. Sports and Youth Strategic Studies Quarterly2018; 17(39): 9-32.

24- Alitabar SH, Ghanbari S, Zadeh MA, Habibi M. The relationship between premarital sex and attitudes toward infidelity. Journal of Family Research2014; 10(2): 255-67.

25- Treas J, Giesen D. Sexual infidelity among married and cohabiting Americans. J Marriage Fam2000; 62(1): 48-60.

26- Ghoreishi Rad F, PourjabarAkhuni F. Relationship between religious commitment and other factors related to tendency toward extra-marital affairs among married students. Health, Spirituality and Medical Ethics2018; 5(2): 45-50.

27- Blow AJ, Hartnett K. Infidelity in committed relationships II: a substantive review. J Marital Fam Ther2005; 31(2): 217-233.

28- Adamopoulou E. New facts on infidelity. Econ Lett2013; 121(3): 458-62.

29- Fathi M, Fekrazad H, Ghaffari G, Bolhari J. Recognizing the fundamental factors of married men engaged in marital infidelity. Social Welfare2014; 13(51): 109-31.

30- Zahedi MJ, Nazoketbar H. Modernization and crisis changes in family (A survey on new problems in family in urban area of Mazandaran province). Social Studies and Research in Iran2014; 3(3): 357-82.

31- Ejtehadi M, Vahedi G. Sociological study of the potential betrayal in marital relations and its effective factors among public and private government employees. Iranian Journal of Sociology2016; 17(14): 105-38.

32- Kamaljou A, Narimani M, Atadokht A, Abolghasami A. The prediction of affairs based on spiritual intelligence, moral intelligence, marital satisfaction, and use of virtual social networks with moderating role of gender. Journal of Family Counseling \& Psychotherapy2017; 2(22): 39-67.

33- Dortaj F, Rajabiyan M, Fatolahi F, Dortaj F. The relationship between the rate of using virtual social networks with loneliness and marital infidelity in students. Educatinal Psychology2018; 14(47): 119-40. 
34- Panahi MH, Tabrizi M. Internet consumption and its impact on the relationship of spouses. Journal of Social Sciences2016; 25(72): 33-70.

35- Sadeghi Fasaei S, Isari M. The sociological study of divorce patterns. Journal of Social Problems of Iran2015;
6(1): 131-56.

36- Khormpour Y, Dehghan AA, Dehghan F, Behjati Asl SF. The relationship between globalization and rethinking among the youth in Yazd city. Journal of Social Development2017; 12(1): 127-50.

Copyright $\odot 2016$ ASP Ins. This open-access article is published under the terms of the Creative Commons Attribution-NonCommercial 4.0

International License which permits Share (copy and redistribute the material in any medium or format) and Adapt (remix, transform, and build upon the material) under the Attribution-NonCommercial terms. 